\title{
FORMAÇÃO INTERDISCIPLINAR DE PROFESSORES: PERCEPÇÕES DE EGRESSOS DE UM CURSO DE CIÊNCIAS NATURAIS E MATEMÁTICA
}

\author{
INTERDISCIPLINARY FORMATION OF TEACHERS: PERCEPTIONS OF \\ GRADUATED STUDENTS FROM A COURSE ON NATURAL SCIENCES AND \\ MATHEMATICS
}

Andreia Cristina Rodrigues Trevisan ${ }^{1}$ ORCID iD: $\underline{0000-0003-0848-759 X}$

\author{
Andréia Dalcin ${ }^{2}$ \\ ORCID iD: $\underline{0000-0003-2488-8801}$
}

\section{RESUMO}

No presente artigo nos propomos a discutir sobre a formação inicial de professores de Ciências e Matemática, com o intuito de indicar potencialidades e fragilidades de uma proposta de formação interdisciplinar posta em ação. Apresentamos um estudo, fruto de uma tese defendida em 2018, realizado com 64 egressos do curso de Licenciatura em Ciências Naturais e Matemática (LCNM) da Universidade Federal de Mato Grosso, Câmpus Universitário de Sinop. A pesquisa apresenta uma abordagem qualiquantitativa, que analisa os dados produzidos por meio de um questionário aplicado a egressos do curso. A diversidade de percepções apresentadas em relação ao percurso formativo vivenciado no curso de LCNM demonstra que não há consenso entre seus egressos. Identificamos que a proposta de curso de LCNM apresenta características inovadoras, bem como potencialidades, a exemplo da aproximação de professores de diferentes áreas e o favorecimento de articulação do conhecimento no currículo. No entanto, possui elementos que necessitam ser problematizados, como a carga horária, o tempo do curso e sua ampla habilitação, que é apontada tanto como o potencial e a fragilidade do curso. Enfatizamos que a formação inicial de professores é um desafio a ser superado e torna-se necessário analisar o conhecimento sistematizado, oriundo de propostas já implementadas, com o intuito de identificar potencialidades e fragilidades do processo formativo.

Palavras-chave: Formação de Professores. Licenciatura Interdisciplinar. Curso de Licenciatura em Ciências Naturais e Matemática. Interdisciplinaridade.

\begin{abstract}
In this article we propose to discuss the initial formation of Science and Mathematics teachers, in order to indicate the strengths and weaknesses of an interdisciplinary formation proposal put into action. We present a study, the result of a thesis defended in 2018, carried out with 64 graduates from the Degree in Natural Sciences and Mathematics (LCNM) at the Federal University of Mato Grosso, University Campus of Sinop. The research presents a qualitative and quantitative approach that analyzes the

\footnotetext{
${ }^{1}$ Doutora em Educação em Ciências e Matemática pela Rede Amazônica de Educação em Ciências e Matemática (REAMEC - UFMT). Docente na Universidade Federal de Mato Grosso (UFMT), Câmpus Universitário de Sinop. Endereço: Av. Alexandre Ferronato, 1200, Setor Industrial, Sinop, Mato Grosso, CEP: 78550-728. E-mail: andreiacr@gmail.com.

${ }^{2}$ Doutora em Educação pela Faculdade de Educação da Universidade Estadual de Campinas (UNICAMP). Docente na Universidade Federal do Rio Grande do Sul (UFRGS), Porto Alegre. Endereço: Av. Paulo da Gama S/n, Bairro Farroupilha, Porto Alegre, CEP 90046-900. E-mail: andreia.dalcin@ufrgs.br.
} 
data produced through questionnaires applied to graduated students of the course. The diversity of perceptions presented, in relation to the formative path experienced in the mentioned course demonstrates that there is no consensus among its students. It was identified that the course proposal presents innovative characteristics, as well as potentialities, such as approximation of teachers from different areas and the favoring of knowledge articulation in the curriculum. However, there are elements that need to be problematized, such as the workload, the time of the course, and its wide occupation area, which is pointed out as both potential and fragility of the course. We emphasize that the initial formation of teachers is a challenge and to overcome it is necessary to analyze the systematized knowledge from proposals already implemented, in order to identify potentialities and weaknesses of the formative process.

Keywords: Teacher Formation. Interdisciplinary Degree. Degree in Natural Sciences and Mathematics. Interdisciplinarity.

\section{INTRODUÇÃO}

A formação de professores é um processo dinâmico, que precisa ser constantemente aprimorado, de modo a atender as demandas que emergem da sociedade. Estamos passando por momentos de redefinições para a educação básica, em que novas orientações têm sido debatidas e promulgadas, influenciando diretamente o processo de formação inicial do docente que irá atuar na escola básica. Nesse contexto, já há alguns anos, temos no Brasil os cursos de licenciatura interdisciplinar, dentre os quais nos detivemos em analisar o de Licenciatura em Ciências Naturais e Matemática (LCNM), ofertado pela Universidade Federal de Mato Grosso, cuja primeira turma colou grau em 2010. Este estudo integrou a tese de doutorado defendida em $2018^{3}$, destacando aspectos não apresentados na mesma.

O objetivo desse artigo é indicar, a partir da percepção de egressos do curso de LCNM, potencialidades e fragilidades da proposta que foi posta em ação e, com isso, fomentar uma discussão sobre a formação inicial interdisciplinar de professores. Para isso, consideramos no processo de análise dos dados da pesquisa a seguinte questão norteadora: o que os egressos do curso de LCNM consideram como pontos fortes e fracos da proposta vivenciada?

Os cursos de licenciatura interdisciplinares nasceram como uma possibilidade de formação inicial diferenciada, com o intuito de propiciar um olhar interdisciplinar tanto para os processos de construção do conhecimento, como para possíveis organizações curriculares na Educação Básica. O Curso de Licenciatura em Ciências Naturais e Matemática foi implantado na Universidade Federal de Mato Grosso, Câmpus de Sinop em 2006, com a intenção de formar

\footnotetext{
3‘"Formação Inicial Interdisciplinar de Professores de Ciências e Matemática: ressonâncias na educação básica", defendida no Programa de Pós-Graduação em Educação em Ciências e Matemática da Rede Amazônica de Educação em Ciências e Matemática (REAMEC).
} 
professores de Ciências e Matemática para atuarem nos anos finais do ensino fundamental e de Matemática, Física ou Química, para atuarem no ensino médio. Este curso é organizado por meio de eixos temáticos e representa uma tentativa de formar professores que aprendam e ensinem Ciências e Matemática de forma integrada e articulada.

Entendemos que é preciso "ouvir" os egressos para que se apreenda sobre um curso, de modo a desenvolver um processo de análise consistente, pois estes estudantes, que vivenciaram e contribuíram para colocar o currículo em movimento, podem indicar as potencialidades e fragilidades desse processo. Nesta perspectiva, optamos, como uma das formas de produção de dados, pelo envio de um questionário online aos egressos do curso de LCNM, utilizando para isso a plataforma do 'Formulários Google'.

O questionário aplicado continha perguntas fechadas e abertas. $\mathrm{O}$ foco nesse momento está na questão aberta de número 7 do formulário ${ }^{4}$. A pesquisa em questão respeitou os princípios éticos, sendo registrado no comitê de ética da instituição proponente da pesquisa, sendo esse o Comitê de Ética em Pesquisa com Seres Humanos da Área das Ciências Humanas e Sociais da Universidade Federal de Mato Grosso (CEP Humanidades) ${ }^{5}$.

Neste artigo apresentaremos alguns dados produzidos por meio desse questionário, com ênfase para a análise das respostas dos egressos quando questionados sobre o curso vivenciado, suas potencialidades e fragilidades, na relação com a proposta do curso. Lembrando que o referido curso caracteriza-se como uma tentativa de mudança do paradigma disciplinar de formação de professores, em prol de uma formação interdisciplinar.

Iniciamos nossa discussão trazendo um panorama histórico da formação de professores de Ciências e Matemática no Brasil, apresentando na sequência um levantamento das Licenciaturas em Ciências Naturais/Natureza (LCN) existentes no Brasil, para então adentrarmos no curso de LCNM e identificar, a partir da perspectiva de egressos, as pontecialidades e fragilidades identificadas por eles, como pontos fortes e fracos.

\section{A FORMAÇÃO DE PROFESSORES DE CIÊNCIAS E MATEMÁTICA NO BRASIL: ALGUNS APONTAMENTOS HISTÓRICOS}

Os estudos de Masola e Allevato (2017) apontam que a educação superior no Brasil possui particularidades e teve um desenvolvimento diferente do restante do continente latinoamericano. Neste contexto, Lima e Leite (2018, p. 144), evidenciam que a formação de

\footnotetext{
${ }^{4} \mathrm{O}$ formulário na íntegra pode ser observado em Trevisan (2018).

${ }^{5}$ CAAE: 58653716.9.0000.5690
} 
professores no Brasil, em nível superior, corresponde "a um processo tardio e concebido com base na racionalidade técnica".

Quando nos referimos à formação de professores no Brasil podemos dizer que um dos seus marcos foi a criação das Escolas Normais, no século XIX. A primeira escola normal brasileira foi criada na Província do Rio de Janeiro em 1835, onde, segundo Tanuri (2000, p. 64) "realizou-se o primeiro ensaio de uma instituição destinada especificamente à formação do pessoal docente para as escolas primárias no Brasil". A autora destaca que as escolas normais, em todas as províncias brasileiras, "tiveram uma trajetória incerta e atribulada, submetidas a um processo contínuo de criação e extinção, para só lograrem algum êxito a partir de 1870” (p. 64). Enfatiza ainda que,

nos períodos de inexistência da escola normal e mesmo durante seu funcionamento, as várias províncias lançaram mão de instrumentos economicamente mais interessantes para recrutamento de docentes: os exames ou concursos. Estes, limitados às matérias do ensino primário e aos "métodos principais de ensino", submetidos a uma política partidária de protecionismo e desprovidos de rigor, só puderam carrear para o magistério um pessoal de baixo nível e exíguas habilitações (TANURI, 2000, p. 65).

Nesse sentido, Soares (2012, p. 29) destaca que as escolas normais acabaram sendo desprestigiadas pelos alunos "visto que os mesmos poderiam chegar ao magistério em menos tempo e sem a necessidade de frequentar aulas".

Para Tanuri (2000, p. 66), é com o ideário de popularização do ensino que as escolas normais passaram "a ser reclamadas com maior constância e coroadas de algum êxito", desencadeando a sua valorização e, consequentemente, o "enriquecimento de seu currículo, ampliação dos requisitos para ingresso e sua abertura ao elemento feminino".

Segundo Gatti, Barreto \& André (2011, p. 97), as escolas normais

continuaram a responder pela formação dos professores para os primeiros anos de ensino fundamental e a educação infantil até recentemente, quando, a partir da Lei $\mathrm{n}^{\mathbf{o}}$ 9394/1996 (LDB), postula-se a formação desses docentes em nível superior, com prazo de dez anos para esse ajuste.

As autoras destacam ainda que a preocupação com a formação de professores para os anos finais do ensino fundamental e ensino médio datam do início do século $\mathrm{XX}$, sendo uma formação voltada para a área disciplinar específica, como pode ser observado em suas colocações. 
No final dos anos de 1930, a partir da formação de bacharéis nas poucas universidades então existentes, acrescenta-se um ano, com disciplinas da área de educação, para a obtenção também da licenciatura, esta dirigida à formação de docentes para o "ensino secundário" (formação que veio a denominar-se popularmente "3+1") (GATTI, BARRETO \& ANDRÉ, 2011, p. 97).

Esse curso se destinava a "formar bacharéis especialistas em educação e, complementarmente, formar professores para as Escolas Normais" (GATTI, BARRETO \& ANDRÉ, 2011, p. 97). O campo de atuação dos profissionais formados nesse curso se mostrava amplo, como destaca as autoras: "os formados nesse curso, pelo currículo da época, também poderiam, por extensão e portaria ministerial, ter a possibilidade de lecionar algumas disciplinas no então ensino secundário, como matemática ou ciências" (p. 98).

Como podemos observar, a formação de professores no Brasil, de forma institucionalizada, se mostra recente, sendo fruto de modelos legitimados no início do século XX. O surgimento de cursos destinados à formação de professores se tornou uma necessidade do país e foi influenciado por alguns acontecimentos. Monteiro e Passos (2013, p. 05) destacam que "o desenvolvimento da industrialização e consequente urbanização no Brasil contribuíram para a criação do Ministério da Educação e Saúde Pública”, que teve como ministro Francisco Campos, autor de importantes reformas na educação brasileira.

Silva (2002) destaca que os cursos específicos visando a formação de professores secundários foi estabelecido com a criação da Faculdade de Filosofia, Ciências e Letras da Universidade de São Paulo (FFCL/USP), em 1934, e da Faculdade Nacional de Filosofia (FNFi), integrante da Universidade do Brasil, no Rio de Janeiro, em 1939. Segundo a autora, "essas duas instituições exerceram uma liderança na orientação dos cursos que começavam a surgir nos demais estados do país, servindo como modelos" (p. 104).

A formação de professores de Ciências e Matemática no Brasil inicialmente acontecia de forma fragmentada, ou seja, no esquema $3+1$, sendo que "desde o início da criação dos cursos de bacharelado e licenciatura, houve uma nítida separação entre conteúdo específico e formação pedagógica" (SILVA, 2002, p. 104). A formação de professores, historicamente, foi tida como algo secundário, sendo o desenvolvimento da pesquisa considerado mais importante. "O professor secundário aparecia como um subproduto altamente especializado daquela instituição que visava, em primeiro lugar, promover a pesquisa" (SILVA, 2002, p. 104).

Como tentativa de romper com esse esquema, segundo Araújo e Vianna (2010), foi publicada, em 1961, a Lei no 4.024/61 que, juntamente com o parecer 292/62, modificam os cursos de licenciatura, "fixando a duração das disciplinas pedagógicas em 1/8 do tempo de 
duração dos mesmos e apontando que elas seriam estudadas ao longo de toda a formação" (ARAÚJO; VIANNA, 2010, p. 04).

Para a história da constituição das licenciaturas no Brasil outro marco importante foi a promulgação da LDB n ${ }^{\circ}$ 5.692/71 que, segundo Araújo e Vianna (2010, p. 05),

fixou a formação mínima para o exercício do magistério e introduziu no cenário educacional brasileiro as Licenciaturas de curta duração, as quais, segundo o Parecer n॰ 895/71, teriam uma duração entre 1200 e 1500 horas, contra as 2200 até 2500 horas da graduação plena.

Para Magalhães Júnior e Oliveira (2005), essa nova lei influenciou o ensino de Ciências, propiciando a criação do primeiro currículo de ensino superior para a formação de professores de Ciências.

\begin{abstract}
Nessa época, surgiram vários cursos de nível superior de licenciatura curta por todo o país, e um de seus moldes mais conhecidos foi a Licenciatura em Ciências, com aproximadamente dois anos de duração. Caso estes profissionais quisessem um título de Licenciatura Plena (LP), poderiam fazer mais um ano de complementação, que poderia ser na área de Biologia, ou Matemática, ou Física, ou Química, processo este que ficou conhecido em várias regiões como plenificação. (MAGALHÃES JÚNIOR; OLIVEIRA, 2005, p. 02).
\end{abstract}

Em 1996, tivemos a promulgação da LDB n ${ }^{\circ}$ 9.394, que promoveu algumas mudanças na educação brasileira, entre elas destacamos a extinção dos cursos de licenciatura curta e a exigência de formação em nível superior, em cursos de licenciatura, de graduação plena, para a atuação na educação básica. Essa nova lei influenciou diretamente a formação de professores, bem como a oferta de cursos destinados a essa formação, principalmente na área de Ciências. Segundo Wortmann (2003), citado em Magalhães Júnior e Oliveira (2005), os cursos de licenciatura curta em Ciências foram alterados para outras áreas das Ciências, em sua maioria para a Biologia. Magalhães Júnior e Oliveira (2005, p. 03) enfatizam que "o país deixou de ter cursos que formassem professores exclusivamente para trabalhar com a disciplina de ciências no ensino fundamental."

Atualmente a formação de professores é regida pelas diretrizes curriculares nacionais para a formação de professores da educação básica, sendo que as orientações mais atuais estão contidas no Parecer CNE/CP n ${ }^{\circ}$ 2/2015 e na Resolução CNE/CP n 2, de $1^{\circ}$ de julho de 2015.

Esses novos documentos preconizam a necessidade de termos um ensino interdisciplinar, eles vêm ao encontro das diretrizes curriculares lançadas em 2002, por meio da Resolução CNE/CP 1, de 18 de fevereiro de 2002, que também já indicava a necessidade de um ensino voltado para a interdisciplinaridade. Outro documento que também se encontra nessa 
vertente são as diretrizes curriculares para o ensino médio, Resolução CEB n ${ }^{\circ} 2$ de 30 de janeiro de 2012.

Podemos dizer que a formação de professores de Ciências e Matemática no Brasil também sofreu influência do Programa de Apoio a Planos de Reestruturação e Expansão das Universidades Federais (REUNI), implantado em 2007, que incentivou o estabelecimento de ações que estimulassem a inovação curricular, por meio da criação de cursos de formação de professores que valorizassem a flexibilização curricular e a interdisciplinaridade. Nesse contexto, surgem as Licenciaturas Interdisciplinares, abarcando a formação de professores nas grandes áreas do conhecimento, o que será discutido na próxima seção.

\section{LICENCIATURAS INTERDISCIPLINARES: UM PANORAMA DAS LICENCIATURAS EM CIÊNCIAS DA NATUREZA/NATURAIS (LCN) EXISTENTES NO BRASIL}

As Licenciaturas Interdisciplinares no Brasil se caracterizam como recentes, gerando ainda muitas dúvidas. O seu objetivo principal é formar professores para atuarem na educação básica nas grandes áreas de conhecimento. Essas se caracterizam como propostas de organização curricular que favorecem a interdisciplinaridade, podendo ser organizadas por áreas de conhecimento, temas ou eixos temáticos. Na resolução $\mathrm{CNE} / \mathrm{CP} \mathrm{n}^{\circ} 2$, de $1^{\circ}$ de julho de 2015, em seu artigo 24, há a indicação de uma regulamentação suplementar para cursos de licenciatura que se organizam em áreas interdisciplinares.

Para este momento, nos interessa discutir sobre os cursos que se destinam a formar professores de Ciências e Matemática. Por isso, procuramos fazer um levantamento de cursos ofertados nesta modalidade, na base de dados do e-MEC ${ }^{6}$, como intuito de termos um panorama dos cursos de licenciatura ofertados no Brasil, que apresentam uma perspectiva interdisciplinar de formação. Cabe ressaltar que há uma divergência na nomenclatura desses cursos, sendo encontrados tanto cursos designados por Licenciatura em Ciências Naturais, quanto por Licenciatura em Ciências da Natureza. Alguns deles habilitam somente para a atuação nos anos finais do ensino fundamental e outros possibilitam, além dessa habilitação em Ciências, a

${ }^{6} \mathrm{O}$ e-MEC foi criado para fazer a tramitação eletrônica dos processos de regulamentação. Pela internet, as instituições de educação superior fazem o credenciamento e o recredenciamento, buscam autorização, reconhecimento e renovação de reconhecimento de cursos. Em funcionamento desde janeiro de 2007, o sistema permite a abertura e o acompanhamento dos processos pelas instituições de forma simplificada e transparente. Fonte: Disponível em: http://emec.mec.gov.br/. Acesso em 10/09/2019. 
habilitação específica para atuar no ensino médio nas disciplinas de Matemática, Física, Química ou Biologia.

Ao iniciarmos nosso levantamento, fizemos uma busca por cursos utilizando a palavrachave "Ciências Naturais", o que nos gerou 90 registros. Depois entramos em cada curso para verificar as informações de forma mais detalhada, considerando somente aqueles que estão em situação "Em Atividade", descartando aqueles em extinção ou extintos e aqueles que passaram por uma mudança na designação Ciências Naturais, mas que continuam na base de dados do eMEC, vinculados à palavra-chave utilizada para a pesquisa. Essa busca resultou no Quadro 1. Cabe lembrar que uma mesma universidade pode ofertar o mesmo curso em vários campi, por isso o registramos somente uma vez para cada instituição.

\begin{tabular}{|c|c|c|c|}
\hline Instituição & Sigla & Nome do curso & Modalidade \\
\hline $\begin{array}{l}\text { UNIVERSIDADE FEDERAL } \\
\text { FLUMINENSE }\end{array}$ & UFF & CIÊNCIAS NATURAIS & Presencial \\
\hline $\begin{array}{l}\text { UNIVERSIDADE DO ESTADO DO } \\
\text { PARÁ }\end{array}$ & UEPA & CIÊNCIAS NATURAIS & Presencial \\
\hline $\begin{array}{l}\text { UNIVERSIDADE FEDERAL DA } \\
\text { PARAÍBA }\end{array}$ & UFPB & CIÊNCIAS NATURAIS & A Distância \\
\hline UNIVERSIDADE FEDERAL DO PARÁ & UFPA & CIÊNCIAS NATURAIS & Presencial \\
\hline UNIVERSIDADE DE BRASÍLIA & UNB & CIÊNCIAS NATURAIS & Presencial \\
\hline $\begin{array}{l}\text { UNIVERSIDADE FEDERAL DO SUL E } \\
\text { SUDESTE DO PARÁ }\end{array}$ & UNIFESSPA & CIÊNCIAS NATURAIS & Presencial \\
\hline $\begin{array}{l}\text { UNIVERSIDADE DO ESTADO DO } \\
\text { AMAPÁ }\end{array}$ & UEAP & CIÊNCIAS NATURAIS & Presencial \\
\hline $\begin{array}{l}\text { UNIVERSIDADE FEDERAL DO } \\
\text { AMAZONAS }\end{array}$ & UFAM & CIÊNCIAS NATURAIS & Presencial \\
\hline UNIVERSIDADE FEDERAL DA BAHIA & UFBA & CIÊNCIAS NATURAIS & Presencial \\
\hline $\begin{array}{l}\text { UNIVERSIDADE FEDERAL DO } \\
\text { MARANHÃO }\end{array}$ & UFMA & $\begin{array}{l}\text { CIÊNCIAS NATURAIS - } \\
\text { BIOLOGIA }\end{array}$ & Presencial \\
\hline $\begin{array}{l}\text { FUNDAÇÃO UNIVERSIDADE } \\
\text { FEDERAL DE RONDÔNIA }\end{array}$ & UNIR & $\begin{array}{l}\text { CIÊNCIAS NATURAIS - } \\
\text { BIOLOGIA }\end{array}$ & A Distância \\
\hline UNIVERSIDADE FEDERAL DO PIAUÍ & UFPI & $\begin{array}{l}\text { CIÊNCIAS NATURAIS E } \\
\text { MATEMÁTICA }\end{array}$ & Presencial \\
\hline $\begin{array}{l}\text { UNIVERSIDADE FEDERAL DE MATO } \\
\text { GROSSO }\end{array}$ & UFMT & $\begin{array}{l}\text { CIÊNCIAS NATURAIS E } \\
\text { MATEMÁTICA }\end{array}$ & A Distância \\
\hline $\begin{array}{l}\text { UNIVERSIDADE FEDERAL DE MATO } \\
\text { GROSSO }\end{array}$ & UFMT & $\begin{array}{l}\text { CIÊNCIAS NATURAIS E } \\
\text { MATEMÁTICA - FÍSICA }\end{array}$ & Presencial \\
\hline $\begin{array}{l}\text { UNIVERSIDADE FEDERAL DE MATO } \\
\text { GROSSO }\end{array}$ & UFMT & $\begin{array}{l}\text { CIÊNCIAS NATURAIS E } \\
\text { MATEMÁTICA - } \\
\text { MATEMÁTICA } \\
\end{array}$ & Presencial \\
\hline $\begin{array}{l}\text { UNIVERSIDADE FEDERAL DE MATO } \\
\text { GROSSO }\end{array}$ & UFMT & $\begin{array}{l}\text { CIÊNCIAS NATURAIS E } \\
\text { MATEMÁTICA - QUÍMICA }\end{array}$ & Presencial \\
\hline $\begin{array}{l}\text { UNIVERSIDADE FEDERAL DO } \\
\text { MARANHÃO }\end{array}$ & UFMA & $\begin{array}{l}\text { CIÊNCIAS NATURAIS - } \\
\text { FÍSICA }\end{array}$ & Presencial \\
\hline
\end{tabular}




\begin{tabular}{|l|c|l|c|}
$\begin{array}{l}\text { INSTITUTO FEDERAL DE EDUCAÇÃO, } \\
\text { CIÊNCIA E TECNOLOGIA DE SÃO } \\
\text { PAULO }\end{array}$ & IFSP & $\begin{array}{l}\text { CIÊNCIAS NATURAIS: } \\
\text { HABILITAÇÃO EM FÍSICA }\end{array}$ & Presencial \\
\hline $\begin{array}{l}\text { INSTITUTO FEDERAL DE EDUCAÇÃO, } \\
\text { CIÊNCIA E TECNOLOGIA DE SÃO } \\
\text { PAULO }\end{array}$ & IFSP & $\begin{array}{l}\text { CIÊNCIAS NATURAIS: } \\
\text { HABILITAÇÃO EM } \\
\text { QUÍMICA }\end{array}$ & Presencial \\
\hline $\begin{array}{l}\text { UNIVERSIDADE FEDERAL DO } \\
\text { MARANHÃO }\end{array}$ & UFMA & $\begin{array}{l}\text { CIÊNCIAS NATURAIS - } \\
\text { QUÍMICA }\end{array}$ & Presencial \\
\hline $\begin{array}{l}\text { UNIVERSIDADE ESTADUAL DE } \\
\text { ALAGOAS }\end{array}$ & UNEAL & $\begin{array}{l}\text { INTERCULTURAL } \\
\text { INDÍGENA EM } \\
\text { MATEMÁTICA E CIÊNCIAS } \\
\text { NATURAIS }\end{array}$ & Presencial \\
\hline $\begin{array}{l}\text { UNIVERSIDADE FEDERAL RURAL DE } \\
\text { PERNAMBUCO }\end{array}$ & UFRPE & $\begin{array}{l}\text { INTERDISCIPLINAR EM } \\
\text { CIÊNCIAS NATURAIS }\end{array}$ & A Distância \\
\hline $\begin{array}{l}\text { UNIVERSIDADE TECNOLÓGICA } \\
\text { FEDERAL DO PARANÁ }\end{array}$ & UTFPR & $\begin{array}{l}\text { INTERDISCIPLINAR EM } \\
\text { CIÊNCIAS NATURAIS }\end{array}$ & Presencial \\
\hline UNIVERSIDADE FEDERAL DO PIAUÍ & UFPI & $\begin{array}{l}\text { INTERDISCIPLINAR EM } \\
\text { CIÊNCIAS NATURAIS }\end{array}$ & Presencial \\
\hline UNIVERSIDADE FEDERAL DO CARIRI & UFCA & $\begin{array}{l}\text { INTERDISCIPLINAR EM } \\
\text { CIÊNCIAS NATURAIS E } \\
\text { MATEMÁTICA }\end{array}$ & Presencial \\
\hline
\end{tabular}

Quadro 1 - Licenciaturas em Ciências Naturais no Brasil.

Fonte: Elaborado pelas autoras a partir de dados do e-MEC.

Da mesma forma fizemos uma busca utilizando a palavra-chave "Ciências da Natureza", o que nos gerou 57 registros. Para esta pesquisa, assim como já comentado anteriormente, consideramos somente os cursos "Em Atividade" e excluímos os registros de cursos extintos e que constavam em duplicidade. É importante destacar a existência, especialmente a partir de 2012, devido a política pública do Procampo ${ }^{7}$, dos cursos de Licenciatura em Educação do Campo, que apresentam como uma das modalidades possíveis à formação em Ciências da Natureza ou Ciências da Natureza e Matemática, e que, além da interdisciplinaridade, operam com a pedagogia da alternância. Os dados podem ser observados no Quadro 2.

\begin{tabular}{|l|c|l|c|}
\hline \multicolumn{1}{|c|}{ Instituição } & Sigla & \multicolumn{1}{c|}{ Nome do curso } & Modalidade \\
\hline $\begin{array}{l}\text { FUNDAÇÃO UNIVERSIDADE } \\
\text { FEDERAL DO PAMPA }\end{array}$ & UNIPAMPA & CIÊNCIAS DA NATUREZA & Presencial \\
\hline FACULDADE SESI-SP DE EDUCAÇÃO & FASESP & CIÊNCIAS DA NATUREZA & Presencial \\
\hline $\begin{array}{l}\text { INSTITUTO FEDERAL DE EDUCAÇÃO, } \\
\text { CIÊNCIA E TECNOLOGIA } \\
\text { FLUMINENSE }\end{array}$ & IF Fluminense & CIÊNCIAS DA NATUREZA & Presencial \\
\hline $\begin{array}{l}\text { UNIVERSIDADE FEDERAL DO } \\
\text { ESTADO DO RIO DE JANEIRO }\end{array}$ & UNIRIO & CIÊNCIAS DA NATUREZA & Presencial \\
\hline UNIVERSIDADE DE SÃO PAULO & USP & CIÊNCIAS DA NATUREZA & Presencial \\
\hline $\begin{array}{l}\text { UNIVERSIDADE FEDERAL DO } \\
\text { RECÔNCAVO DA BAHIA }\end{array}$ & UFRB & CIÊNCIAS DA NATUREZA & Presencial \\
\hline
\end{tabular}

${ }^{7}$ Programa de Apoio à Formação Superior em Licenciatura em Educação do Campo (Procampo), que integrou a Política Nacional de Educação do Campo, instituída pelo Decreto n. 7352/2010. 


\begin{tabular}{|c|c|c|c|}
\hline UNIVERSIDADE FEDERAL DO PIAUÍ & UFPI & CIÊNCIAS DA NATUREZA & $\begin{array}{c}\text { Presencial e A } \\
\text { Distância }\end{array}$ \\
\hline $\begin{array}{l}\text { FUNDAÇÃO UNIVERSIDADE } \\
\text { FEDERAL DO VALE DO SÃO } \\
\text { FRANCISCO }\end{array}$ & UNIVASF & CIÊNCIAS DA NATUREZA & Presencial \\
\hline $\begin{array}{l}\text { INSTITUTO FEDERAL DE EDUCAÇÃO, } \\
\text { CIÊNCIA E TECNOLOGIA DE MATO } \\
\text { GROSSO }\end{array}$ & IFMT & CIÊNCIAS DA NATUREZA & Presencial \\
\hline $\begin{array}{l}\text { INSTITUTO FEDERAL DE EDUCAÇÃO, } \\
\text { CIÊNCIA E TECNOLOGIA DO RIO } \\
\text { GRANDE DO SUL }\end{array}$ & IFRS & $\begin{array}{l}\text { CIÊNCIAS DA NATUREZA - } \\
\text { BIOLOGIA E QUÍMICA }\end{array}$ & Presencial \\
\hline $\begin{array}{l}\text { UNIVERSIDADE FEDERAL DA } \\
\text { INTEGRAÇÃO LATINO-AMERICANA }\end{array}$ & UNILA & $\begin{array}{l}\text { CIÊNCIAS DA NATUREZA - } \\
\text { BIOLOGIA, FÍSICA E } \\
\text { QUÍMICA }\end{array}$ & Presencial \\
\hline $\begin{array}{l}\text { INSTITUTO FEDERAL DE EDUCAÇÃO, } \\
\text { CIÊNCIA E TECNOLOGIA DO RIO } \\
\text { GRANDE DO NORTE }\end{array}$ & IFRN & $\begin{array}{l}\text { CIÊNCIAS DA NATUREZA E } \\
\text { MATEMÁTICA }\end{array}$ & Presencial \\
\hline $\begin{array}{l}\text { UNIVERSIDADE DA INTEGRAÇÃO } \\
\text { INTERNACIONAL DA LUSOFONIA } \\
\text { AFRO-BRASILEIRA }\end{array}$ & UNILAB & $\begin{array}{l}\text { CIÊNCIAS DA NATUREZA E } \\
\text { MATEMÁTICA }\end{array}$ & Presencial \\
\hline $\begin{array}{l}\text { UNIVERSIDADE FEDERAL DO RIO } \\
\text { GRANDE DO SUL }\end{array}$ & UFRGS & \begin{tabular}{|l|} 
CIÊNCIAS DA NATUREZA \\
PARA OS ANOS FINAIS DO \\
ENSINO FUNDAMENTAL \\
\end{tabular} & A Distância \\
\hline $\begin{array}{l}\text { INSTITUTO FEDERAL DE EDUCAÇÃO, } \\
\text { CIÊNCIA E TECNOLOGIA DE MATO } \\
\text { GROSSO }\end{array}$ & IFMT & $\begin{array}{l}\text { CIÊNCIAS DA NATUREZA - } \\
\text { QUÍMICA }\end{array}$ & Presencial \\
\hline UNIVERSIDADE FEDERAL DO PIAUÍ & UFPI & $\begin{array}{l}\text { EDUCAÇÃO DO CAMPO - } \\
\text { CIÊNCIAS DA NATUREZA } \\
\end{array}$ & Presencial \\
\hline $\begin{array}{l}\text { INSTITUTO FEDERAL DE EDUCAÇÃO, } \\
\text { CIÊNCIA E TECNOLOGIA } \\
\text { FARROUPILHA }\end{array}$ & IFFarroupilha & $\begin{array}{l}\text { EDUCAÇÃO DO CAMPO - } \\
\text { CIÊNCIAS DA NATUREZA }\end{array}$ & Presencial \\
\hline $\begin{array}{l}\text { UNIVERSIDADE FEDERAL DO RIO } \\
\text { GRANDE DO SUL }\end{array}$ & UFRGS & $\begin{array}{l}\text { EDUCAÇÃO DO CAMPO - } \\
\text { CIÊNCIASS DA NATUREZA }\end{array}$ & Presencial \\
\hline $\begin{array}{l}\text { FUNDAÇÃO UNIVERSIDADE } \\
\text { FEDERAL DA GRANDE DOURADOS }\end{array}$ & UFGD & $\begin{array}{l}\text { EDUCAÇÃO DO CAMPO - } \\
\text { CIÊNCIAS DA NATUREZA }\end{array}$ & Presencial \\
\hline UNIVERSIDADE FEDERAL DE VIÇOSA & UFV & \begin{tabular}{|l|} 
EDUCAÇÃO DO CAMPO - \\
CIÊNCIAS DA NATUREZA \\
\end{tabular} & Presencial \\
\hline $\begin{array}{l}\text { UNIVERSIDADE FEDERAL DO } \\
\text { RECÔNCAVO DA BAHIA }\end{array}$ & UFRB & $\begin{array}{l}\text { EDUCAÇÃO DO CAMPO - } \\
\text { CIÊNCIAS DA NATUREZA E } \\
\text { MATEMÁTICA } \\
\end{array}$ & Presencial \\
\hline $\begin{array}{l}\text { UNIVERSIDADE REGIONAL DO } \\
\text { CARIRI }\end{array}$ & URCA & $\begin{array}{l}\text { EDUCAÇÃO DO CAMPO - } \\
\text { CIÊNCIAS DA NATUREZA E } \\
\text { MATEMÁTICA }\end{array}$ & Presencial \\
\hline $\begin{array}{l}\text { UNIVERSIDADE FEDERAL DE } \\
\text { RORAIMA }\end{array}$ & UFRR & \begin{tabular}{|l} 
EDUCAÇÃO DO CAMPO - \\
CIÊNCIAS DA NATUREZA E \\
MATEMÁTICA \\
\end{tabular} & Presencial \\
\hline $\begin{array}{l}\text { UNIVERSIDADE ESTADUAL DO } \\
\text { OESTE DO PARANÁ }\end{array}$ & UNIOESTE & $\begin{array}{l}\text { EDUCAÇÃO DO CAMPO - } \\
\text { EM CIÊNCIAS DA } \\
\text { NATUREZA E } \\
\text { MATEMÁTICA } \\
\end{array}$ & Presencial \\
\hline UNIVERSIDADE FEDERAL DE GOIÁS & UFG & \begin{tabular}{|l|} 
EDUCAÇÃO \\
INTERCULTURAL - \\
CIÊNCIAS DA NATUREZA \\
\end{tabular} & Presencial \\
\hline $\begin{array}{l}\text { UNIVERSIDADE FEDERAL DO SUL DA } \\
\text { BAHIA }\end{array}$ & UFSB & \begin{tabular}{|l} 
INTERDISCIPLINAR EM \\
CIÊNCIAS DA NATUREZA E \\
SUAS TECNOLOGIAS \\
\end{tabular} & Presencial \\
\hline
\end{tabular}




\begin{tabular}{|l|c|l|c|}
$\begin{array}{l}\text { UNIVERSIDADE FEDERAL DA } \\
\text { FRONTEIRA SUL }\end{array}$ & UFFS & $\begin{array}{l}\text { INTERDISCIPLINAR EM } \\
\text { EDUCAÇÃO DO CAMPO: } \\
\text { CIÊNCIAS DA NATUREZA }\end{array}$ & Presencial \\
\hline $\begin{array}{l}\text { UNIVERSIDADE FEDERAL DE } \\
\text { RORAIMA }\end{array}$ & UFRR & $\begin{array}{l}\text { LICENCIATURA } \\
\text { INTERCULTURAL - } \\
\text { CIÊNCIAS DA NATUREZA }\end{array}$ & Presencial \\
\hline
\end{tabular}

Quadro 2 - Licenciaturas em Ciências da Natureza no Brasil. Fonte: Elaborado pelas autoras a partir de dados do e-MEC.

É possível perceber que há uma diversidade de cursos de formação de professores, hoje, no Brasil, pautados pela interdisciplinaridade. Mas também é importante frisar que pouco se sabe sobre estes cursos. Imbernon et al (2011), aponta que em um debate sobre ensino de Ciências, ocorrido no encontro do curso de Licenciatura em Ciências Naturais da FUP Universidade de Brasília, câmpus Planaltina, em agosto de 2008, é possível fazer a seguinte observação: "percebeu-se, naquela oportunidade, que desconhecíamos quantos cursos existiam e de como estavam sendo articulados os projetos políticos pedagógicos.” (p. 86).

Neste sentido, compreendemos que muitas coisas ainda precisam ser problematizadas e até mesmo avaliadas na formação de professores que se paute na interdisciplinaridade, referente a cursos organizados por área de conhecimento, por temas ou por eixos temáticos. O avanço nas discussões está relacionado com o que conhecemos sobre esses cursos, que precisam ser compreendidos nas suas especificidades locais e culturais. Nesta perspectiva, direcionamos nosso olhar para o curso Licenciatura em Ciências Naturais e Matemática (LCNM) da Universidade Federal de Mato Grosso, Câmpus Universitário de Sinop.

\section{O CURSO DE LICENCIATURA EM CIÊNCIAS NATURAIS E MATEMÁTICA DA UNIVERSIDADE FEDERAL DE MATO GROSSO: PERCEPÇÕES DE EGRESSOS}

O Câmpus Universitário de Sinop foi criado em 2006, por meio do processo de expansão das universidades federais do país. O curso de Licenciatura em Ciências Naturais e Matemática é fruto de uma proposta de formação de professores pensada por um grupo de professores do Câmpus de Cuiabá, interessados em uma formação diferenciada. Essa proposta foi implantada, a princípio, para a formação de professores que atuavam em sala, mas que não tinham formação específica nas áreas de Ciências da Natureza e Matemática.

O curso LCNM possui oito módulos, organizados por eixos temáticos, sendo que nos quatro primeiros a formação busca dar fundamentação para o trabalho com Ciências e Matemática no ensino fundamental e, nos quatro últimos módulos, os alunos são direcionados para habilitações específicas, Matemática, Física ou Química, buscando dar suporte teórico para 
o trabalho com essas disciplinas no ensino médio. A organização do curso pode ser visualizada no Quadro 3.

O curso LCNM utiliza a história das ciências como forma de transversalizar o currículo e objetiva, segundo seu Projeto Pedagógico, formar um professor que desenvolva uma visão integrada e totalitária das ciências.

\section{Módulo 1 - Introdução as Ciências da Natureza e Matemática \\ Módulo 2 - A Terra e o Universo \\ Módulo 3 - Biodiversidade Módulo 4 - Manutenção dos Sistemas Vivos}

Habilitação Matemática

Módulo 5 - Números e Formas: a matemática da Antiguidade à Idade Média

Módulo 6 - O Renascimento e a Ciência Moderna: a Matemática no Renascimento

Módulo 7 - O desenvolvimento da Matemática após a invenção do cálculo e da álgebra moderna Módulo 8 - A Matemática nos séculos XX e XXI: a Ciência do século XXI e a teoria da complexidade

\section{Habilitação Física}

Módulo 5 - Princípios

Fundamentais da Física desde a

Antiguidade Clássica até a época de Newton

Módulo 6 - Física nos séculos XVIII e XIX

Módulo 7 - Física Moderna, século XX

Módulo 8 - A Ciência do Século XXI e a Teoria da Complexidade

\section{Habilitação Química}

Módulo 5 - Evolução da Química desde a tecnologia paleolítica à química newtoniana

Módulo 6 - Lavoisier e a revolução Química até o século XX, evolução da química orgânica e inorgânica

Módulo 7 - Surgimento e evolução da química analítica, da bioquímica e da físico-química

Módulo 8 - A Química do século

XXI: a Ciência do século XXI e a

Teoria da Complexidade

Quadro 3 - Organização do curso LCNM.

Fonte: Elaborado pelas autoras a partir da proposta do curso.

Nos dedicamos, neste artigo, a apresentar as percepções de egressos sobre a formação interdisciplinar, tendo em vista que eles vivenciaram o curso e podem contribuir para compreendermos melhor a proposta posta em ação.

Os dados foram produzidos por meio da aplicação de questionário online a egressos do curso, que colaram grau entre os semestres letivos 2010/1 e 2015/2. Foi enviado um questionário, através do "Formulários Google" a 98 egressos do curso, sendo que o primeiro contato com esses egressos aconteceu em novembro de 2016 e o último contato em fevereiro de 2017. O questionário completo continha cerca de 23 perguntas, sendo 10 fechadas, de múltipla escolha, e 13 abertas, ou seja, subjetivas. No entanto, destacamos que a quantidade de perguntas para cada egresso variava conforme as respostas que eram dadas, diferenciando as perguntas para aqueles que estavam atuando na educação básica e para os que não estavam ou nunca atuaram como docentes.

O questionário foi utilizado como meio de produção de dados iniciais dos egressos do curso LCNM e possibilitou a escolha de colaboradores para um segundo momento da pesquisa, em que utilizamos entrevistas narrativas como forma de produção de dados e a Análise Textual 
Discursiva (ATD) como forma de análise desses dados. Para este momento, nos ateremos aos dados produzidos somente por meio do questionário, relacionados a formação interdisciplinar vivenciada no curso LCNM.

A pergunta do questionário que apresentaremos se refere a formação interdisciplinar vivenciada no curso LCNM da Universidade Federal de Mato Grosso, Câmpus Sinop. Ressaltamos que as perguntas fechadas foram organizadas e tabuladas conforme as respostas estabelecidas a priori no questionário e as perguntas abertas foram organizadas de forma a agrupar respostas que possuíam aproximações de sentido, estabelecendo classificações que emergiram dos dados que foram produzidos, sendo estabelecidos a posteriori.

Nesse processo de produção de dados, obtivemos como retorno 64 questionários respondidos. Destes respondentes 27 são egressos da habilitação Matemática, 16 da Física e 21 da Química. Entre as várias questões problematizadas pelo questionário, trazemos para este artigo a análise da questão: "O que considera como pontos fortes (potencialidades) e fracos (fragilidades) do curso Licenciatura em Ciências Naturais e Matemática da Universidade Federal de Mato Grosso, Câmpus Sinop?”. As respostas podem constar em mais de um agrupamento, ultrapassando o total de 64 respostas.

Em relação aos pontos fortes, as respostas mais recorrentes se referiram aos docentes do curso, sendo que foram apontados como bem preparados e comprometidos com a proposta. Também houve respostas que apontaram a matriz curricular do curso e sua organização como pontos favoráveis; sinalizando para a interdisciplinaridade trabalhada no curso, ou pelo menos a tentativa de trabalho nessa perspectiva; a ampla formação para o mercado de trabalho; a sua estrutura física; e o fato de ser um curso noturno. Os dados podem ser observados no gráfico da Figura 1.

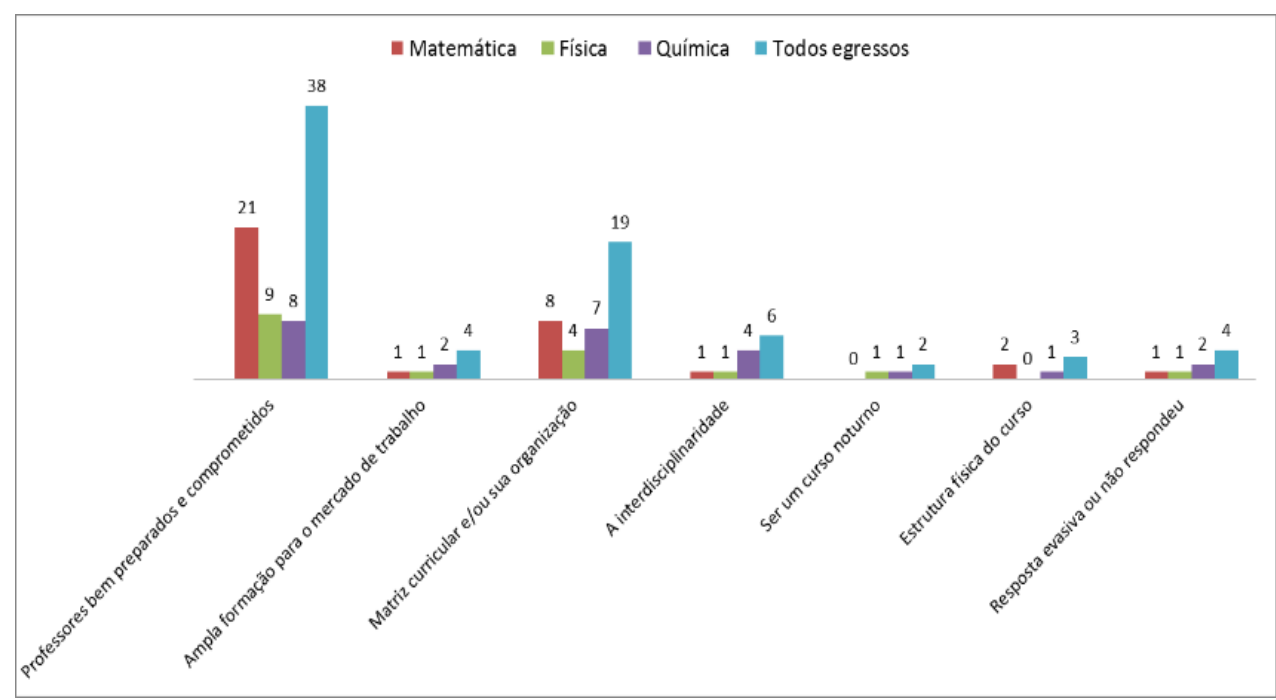

Figura 1 - Pontos fortes do curso LCNM apontados pelos egressos Fonte: Elaborado pelas autoras. 
Para exemplificar, trazemos a seguir algumas respostas que geraram estes agrupamentos

na Figura 1. Utilizamos a letra R, seguido de um número, para identificar os participantes da pesquisa. A letra $\mathrm{R}$ faz referência à palavra respondente e o número indica a ordem em que as respostas foram recebidas.

\begin{tabular}{|c|c|}
\hline CATEGORIAS & EXEMPLOS DE RESPOSTAS DOS EGRESSOS \\
\hline $\begin{array}{l}\text { Professores bem } \\
\text { preparados e } \\
\text { comprometidos }\end{array}$ & $\begin{array}{l}\text { Competência e comprometimento dos professores }(\mathrm{R} 19) \text {. } \\
\text { Professores capacitados e estrutura física (R42). } \\
\text { Pontos fortes são os professores altamente capacitados para ministrar as } \\
\text { matérias }(\mathrm{R} 3) \text {. } \\
\text { Eu acho que um ponto forte são os professores atuantes que fazem parte do curso } \\
\text { e que são bons profissionais da área }(\mathrm{R} 12) \text {. } \\
\text { Como pontos fortes, os professores, que apesar dos pesares - e voltando ao curso } \\
\text { de Física, não ter a disposição equipamentos; livros e outros para proporcionar } \\
\text { aos alunos um ensino mais pesado e voltado à experimentação - são muito } \\
\text { esforçados e fazem milagres }(\mathrm{R} 46) \text {. } \\
\text { Fortes: } \text { O empenho dos professores, o grau de cobrança para atingir um nível de } \\
\text { conhecimento aceitável. O estágio dividido pelos semestres, facilita para quem } \\
\text { trabalha e estuda }(\mathrm{R} 60) \text {. }\end{array}$ \\
\hline $\begin{array}{l}\text { Matriz curricular e/ou } \\
\text { sua organização }\end{array}$ & 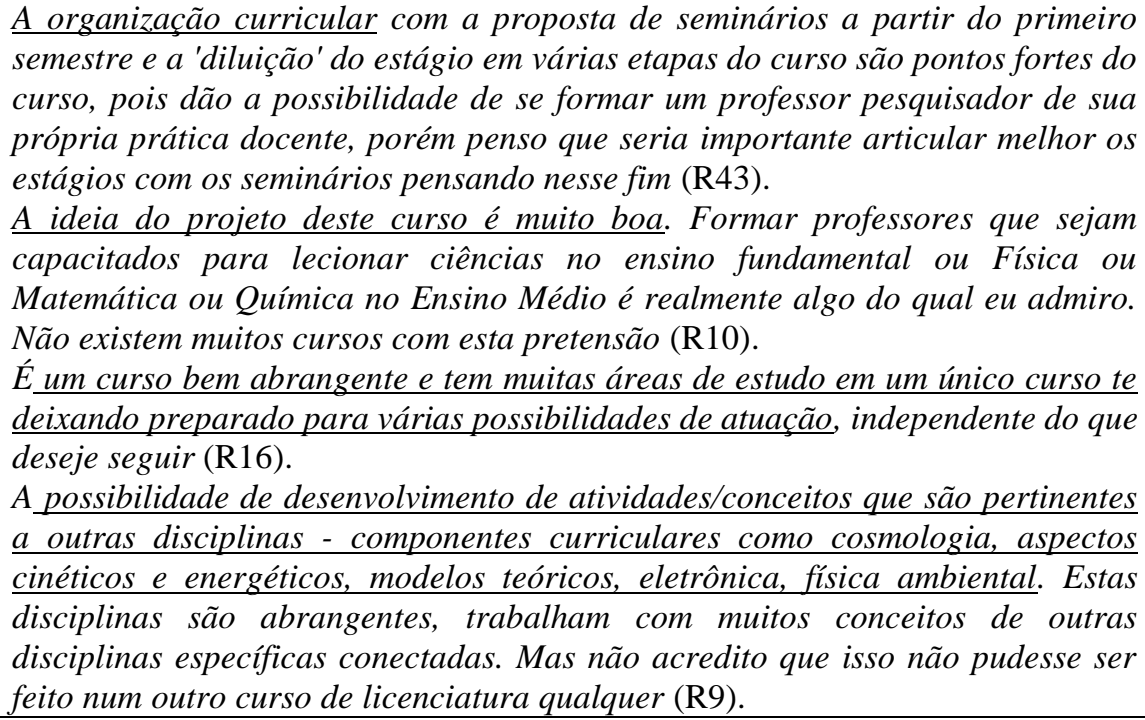 \\
\hline $\begin{array}{l}\text { Ampla formação para o } \\
\text { mercado de trabalho }\end{array}$ & $\begin{array}{l}\text { Forte é o fato da Habilitação para Matemática Ciências e Física, isto abre as } \\
\text { portas para vários programas de Pós-graduação e trabalho }(\mathrm{R} 40) \text {. } \\
\text { A estrutura do curso, a maioria dos professores e a possibilidade de mercado de } \\
\text { trabalho durante e após a formação do curso }(\mathrm{R} 2) \text {. } \\
\hat{E} \text { um curso bem abrangente e tem muitas áreas de estudo em um único curso te } \\
\text { deixando preparado para várias possibilidades de atuação, independente do que } \\
\text { deseje seguir }(\mathrm{R} 16) \text {. }\end{array}$ \\
\hline Estrutura física do curso & $\begin{array}{l}\text { Fortes: ótimos professores, boa estrutura (R57). } \\
\text { Ponto forte é a estrutura e o reconhecimento (R23). }\end{array}$ \\
\hline Ser um curso noturno & $\begin{array}{l}\text { Creio que posso elencar alguns pontos fortes no curso de Licenciatura, a saber: } \\
\text { professores capacitados para ministrar o curso e horário flexível com a jornada } \\
\text { de trabalho dos acadêmicos } \\
\text { Pontos fortes: incentivo à pesquisa e trabalho científico; periodo noturno } \\
\text { (R13). }\end{array}$ \\
\hline Interdisciplinaridade & $\begin{array}{l}\text { Interdisciplinaridade, boa preparação para redação científica, bom preparo em } \\
\text { disciplinas didáticas e estágios supervisionados (R36). } \\
\text { Interdisciplinaridade que tanto é buscado pela maioria dos professores e pelo } \\
\text { próprio PPC do curso (R53). }\end{array}$ \\
\hline
\end{tabular}


Resposta evasiva ou não $\quad$ A disciplina de Química é desafiadora e causa curiosidade aos alunos - ponto respondeu forte (R29).

Quadro 4 - Algumas respostas dos egressos em relação aos pontos fortes do curso. Fonte: Elaborado pelas autoras.

Destacamos que, segundo as falas dos egressos, é perceptível a dedicação dos professores que trabalham ou trabalharam no curso. Podemos apreender, por meio do relato de R46, que as condições de infraestrutura não eram as ideais por ocasião da implementação do curso, mesmo assim, havia o empenho para que o curso acontecesse da melhor maneira possível. Atuavam no curso cerca de 13 professores por ocasião de sua implantação. A fala dos egressos nos diz que não basta uma proposta curricular diferenciada, é preciso o comprometimento dos professores no sentido de materializar a proposta em ações pedagógicas no cotidiano do curso, e, neste sentido, as respostas acenam para um comprometimento dos professores que atuaram no referido curso e se comprometeram com ele, mantendo posturas e atitudes favoráveis a implantação da proposta.

Destacamos que a formação de professores atualmente exige posturas mais flexíveis a mudanças, ou seja, precisamos nos atentar ao que vem acontecendo na sociedade, e esses professores se mostraram engajados com a proposta do curso; consideramos necessário a busca pela inovação. Veiga e Viana (2012) apontam que a formação do professor que inova, entre outras coisas, precisa apostar que inovar é possível, mesmo com todas as dificuldades cotidianas que possivelmente aparecerão.

As falas fizeram referência a matriz curricular do curso LCNM, que se caracteriza como uma tentativa de inovação. Segundo as mesmas, e o que consta no Projeto Pedagógico do Curso (PPC), a organização por eixos temáticos possibilita um trabalho integrador. Consta no PPC que "as disciplinas e componentes curriculares são organizadas de modo a atender eixos temáticos de relevância curricular e de significado social” (UFMT, 2009, p. 30), o que poderá desencadear na articulação entre elas.

Como exemplo, o primeiro módulo ao tratar da história das ciências, estará paralelamente refletindo sobre a identidade do homem, principal protagonista dessa história. Por sua vez serão abordadas as teorias relativas à construção do conhecimento humano e suas aplicações no processo ensino-aprendizagem (UFMT, 2009, p. 30).

Ressaltamos que na proposta de curso LCNM a perspectiva interdisciplinar para o ensino de Ciências e Matemática é destacada principalmente nos módulos comuns do curso. 
A dimensão interdisciplinar do ensino de Ciências Naturais e Matemática e a efetivação dessa formação comum e necessária ao professor das ciências da natureza e matemática é estabelecida, sobretudo em disciplinas comuns às habilitações em Matemática, Física e Química (UFMT, 2009, p. 30).

No entanto, também é importante destacar a fala de R9, quando diz: "mas não acredito que isso não pudesse ser feito num outro curso de licenciatura qualquer”. Ele deixa transparecer que a proposta se mostra interessante, mas também enfatiza que um olhar interdisciplinar, o qual articule diferentes conceitos, conteúdos e metodologias das ciências não possa estar presente em outras organizações curriculares, ou seja, em outros cursos de licenciatura. Esta fala nos remete a uma percepção de interdisciplinaridade, em uma perspectiva epistemológica, para além de uma organização curricular. No entanto, não podemos deixar de indicar a dificuldade que as instituições universitárias têm tido "para romper com estruturas curriculares fragmentadas e desconectadas" (BORGES, 2012, p. 37).

Outro aspecto que foi evidenciado nas falas dos egressos foi o fato de o curso abrir diferentes possibilidades de atuação no mercado, tendo em vista que se propõe a dar uma formação que possibilite a atuação de seu egresso como professor de Ciências e Matemática nos anos finais do ensino fundamental e de Matemática, Física ou Química no ensino médio. O curso LCNM foi escolhido para ser implantado em Sinop devido a sua ampla possibilidade de formação, assim como pode ser observado em seu projeto.

\footnotetext{
A região norte do estado de Mato Grosso, bem como todo o estado, possui uma grande carência de docentes para atuação na área de Ciências Naturais, Matemática, Física e Química na educação básica, destacando que quase não existem profissionais formados nesta área. Por esse motivo as aulas são na maioria das vezes ministradas por profissionais de outras áreas ou por pessoas sem formação em nível superior, o que prejudica o aprendizado dos alunos interferindo significativamente na qualidade de ensino da região (UFMT, 2009, p. 12-13).
}

O fato de ser um curso noturno também foi mencionado. Ao analisarmos o perfil dos ingressantes do curso, é possível perceber que vários são trabalhadores que exercem diferentes ações ao longo do dia e que precisam estudar a noite.

Assim como uma proposta de curso, possivelmente, detém pontos fortes, que permitem explicitar as potencialidades de determinado curso, também, possivelmente, apresenta fragilidades, que ao serem consideradas e analisadas podem direcionar estratégias de aprimoramento do processo formativo proposto. É com esse intuito que questionamos os egressos do curso LCNM sobre os pontos fracos do curso vivenciado. Nesse sentido, alguns pontos que apareceram como fortes também foram mencionados como fracos. 
Os agrupamentos apontam para os seguintes elementos a serem aprimorados no curso: a organização e a matriz curricular do curso, elemento mais frequentemente mencionado, seguido por questões que consideramos externas ao curso como: estrutura física e recursos humanos, os períodos de greves na universidade, a falta de valorização profissional, bem como a aceitação do mercado de trabalho da dupla habilitação; questões referentes aos professores do curso e suas metodologias; a pouca utilização dos laboratórios ou aulas práticas; a duração do curso e sua realização no período noturno; ficando empatado a questão referente a falta de eventos, palestras ou projetos relacionados ao curso e o índice de evasão do curso; a falta de interdisciplinaridade; e, por último, a falta de inserção no cotidiano escolar, como pode ser observado no gráfico da Figura 2.

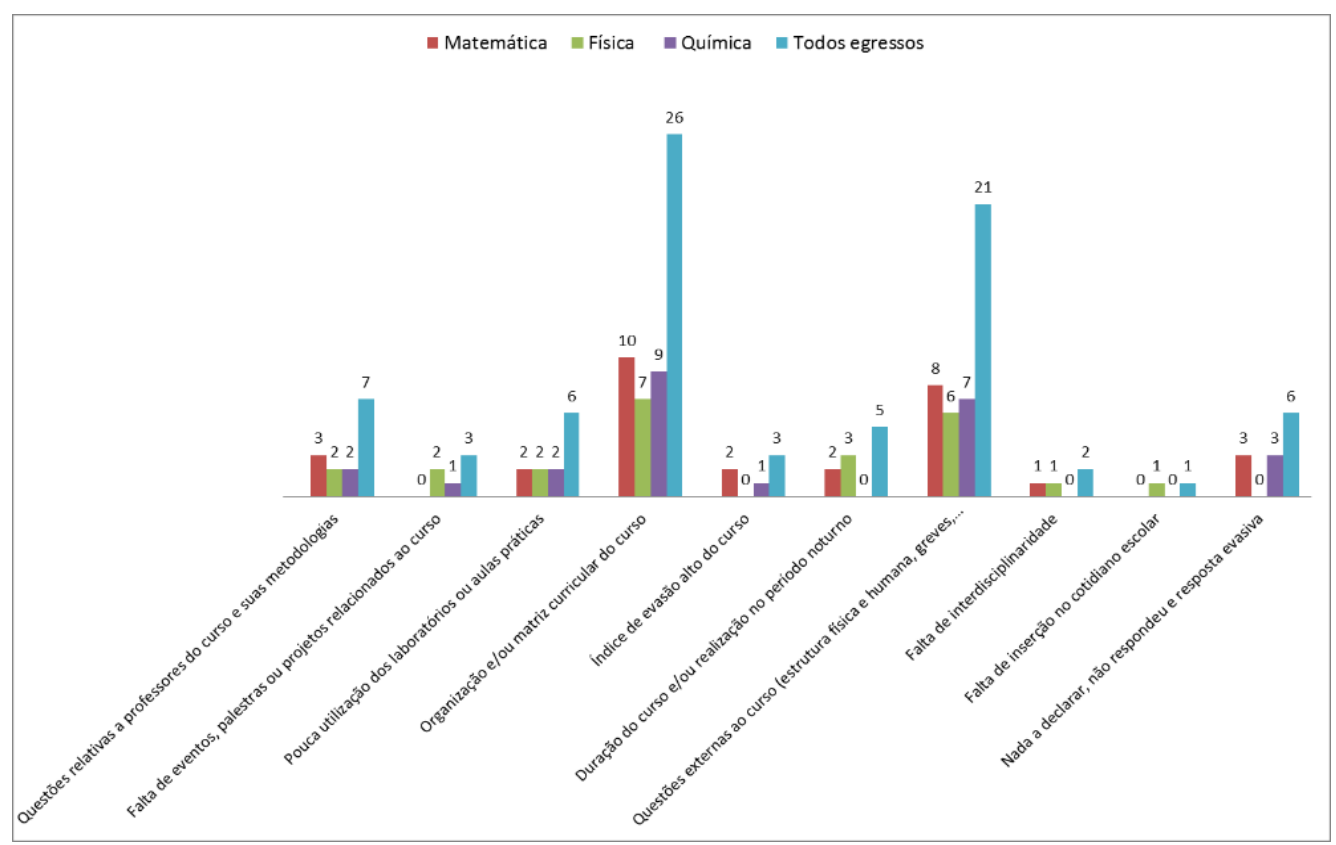

Figura 2 - Pontos fracos do curso LCNM apontados pelos egressos. Fonte: Elaborado pelas autoras.

A seguir também trazemos algumas respostas dadas pelos egressos:

\begin{tabular}{|c|c|}
\hline CATEGORIAS & EXEMPLOS DE RESPOSTAS DOS EGRESSOS \\
\hline & $\begin{array}{l}\text { Carga horária para determinadas disciplinas, pois muitas das vezes } \\
\text { acaba sendo insuficiente para passar os conteúdos (R2). } \\
\text { A divisão entre os dois primeiros anos para os dois últimos, é um baque } \\
\text { e tanto para a química e física, a matemática nem tanto pois desde o } \\
\text { primeiro semestre já se estuda matemática (R15). } \\
\text { Pouca carga horária de Física ofertada ao núcleo comum do curso (2 } \\
\text { primeiros anos) (R19). } \\
\text { Como minha habilitação foi em matemática não vi quase nada de física, } \\
\text { química sim, mas física faltou muita coisa até mesmo para o ensino de } \\
\text { ciências nos anos finais do ensino fundamental (R60). }\end{array}$ \\
\hline
\end{tabular}




\section{Organização e/ou matriz curricular do curso}

O foco mínimo em matérias de docência, história da Educação, muito enfoque em matérias de matemática nos dois primeiros anos e falta de apoio administrativo no período noturno (R11).

Avalio que o curso deveria se preocupar com disciplinas mais básicas e ter uma atenção especial referente a elas, aumentar cargas horárias e promover o estudo da habilitação específica desde o início do curso através de atividades extras ou disciplinas específicas. Desta maneira tem-se um estudo mais gradativo dos conteúdos e talvez facilite o andamento para os alunos (R32).

Penso que as disciplinas comuns, dos dois primeiros anos, preparamo futuro professor para atuar em ciências e matemática no Ensino Fundamental, mas o estágio na disciplina que não é da habilitação do graduando deveria merecer uma atenção especial (talvez uma carga horária maior ou mais professores para acompanhar). A cada semestre o curso tem uma espécie de "eixo comum", "tema central", ou algo assim, e isso me parece muito bom, mas a articulação entre as disciplinas precisa melhorar, pelo que me recordo apenas a "Terra $e$ Universo" que tivemos uma articulação interessante nesse sentido. E se for pensar que são poucos os alunos que fazem as matérias direitinho nos semestres, esse tema central não faz muito sentido (R43).

Grade curricular com tempo insuficiente para todas as disciplinas, poderia reduzir, retirar algumas e agregar mais tempo nas específicas (habilitações) (R17).

Pontos fracos: a grade curricular, as greves, a falta de estrutura (R25). Fraco a valorização do curso (R37).

Fracos: como sou da $1^{a}$ turma, falta de estrutura física (R50).

Ponto fraco a greve que atrapalha muito (R54).

Durante a minha graduação sentimos muito a falta de estrutura física, laboratórios, visitações. Sai do curso muito mais preparada para a pesquisa que para a sala de aula (R44).

Como pontos fracos: falta de literatura disponível na Biblioteca; laboratórios mal equipados, grade curricular defasada, poderia haver mais matérias nas áreas específicas, .... (R46).

Fracos: pelo menos nos anos iniciais da minha graduação teve muitas trocas de professores ao longo do semestre o que dificultava a sequência de conteúdos (R16).

Um ponto fraco que percebi enquanto ainda estava cursando é a falta de estrutura para aulas práticas em laboratório (R3).

Ponto fraco falta estrutura na época (R7).

Ponto fraco: Não me aceitaram como professora de Ciências, pois minha habilitação era em matemática. Só posso exercer se não estiver profissional habilitado em ciências (R63).

Pontos fracos: a grade curricular, as greves, a falta de estrutura (R25).

Pontos Fracos: Alguns Professores não conseguem expor aquilo que pensam e sabem aos seus alunos, ou seja, sabem muito porém passar isso pra frente, é dificultado em alguns momentos (R1).

$O$ ponto fraco é que até mesmo alguns professores não acreditam no potencial do curso, para o que ele foi pensado de fato: ser uma graduação para formar professores de Ciências Naturais e Matemática capazes de atuar suprindo as necessidades existentes no ensino básico da educação brasileira (R33).

Pontos fracos: pouco aprofundamento nas disciplinas específicas, pouco uso dos laboratórios (R36).

Pontos fracos: pouca utilização do laboratório de informática e de matemática, que poderiam ter sido melhor aproveitado durante a graduação (R5).

O ponto ruim é o tempo do curso deveria ser 5 anos, desta forma muito dos conteúdos ficaram muito superficiais (R40).

Ponto fraco seria a duração do curso que se torna curto diante da formação em três áreas específicas (R12). 


\begin{tabular}{|c|c|}
\hline & Ponto fraco; a evasão acadêmica, o período noturno (R26). \\
\hline $\begin{array}{l}\text { Falta de eventos, palestras ou } \\
\text { projetos relacionados ao curso }\end{array}$ & $\begin{array}{l}\text { Um outro ponto que acho importante citar é que não se faz projetos de } \\
\text { pesquisa. Eu vejo isso como algo necessário. O mesmo vale para } \\
\text { eventos. O curso deveria sediar mais eventos, palestras, projetos }(\mathrm{R} 35) \text {. } \\
\text { FRACOS: a universidade não fornece muitos eventos para contagem } \\
\text { das horas complementares e também não valoriza os alunos do período } \\
\text { noturno, tendo em vista que a parte administrativa da universidade só } \\
\text { funciona de dia (R49). }\end{array}$ \\
\hline Índice de evasão alto do curso & $\begin{array}{l}\text { Pontos fracos: índice de evasão alto (R21). } \\
\text { Ponto fraco; a evasão acadêmica, o período noturno (R26). }\end{array}$ \\
\hline Falta de interdisciplinaridade & $\begin{array}{l}\text { Forte a tentativa da interdisciplinaridade e fraco a falta dela (R27). } \\
\text { Ponto fraco: O projeto não é colocado em prática. Poucos professores } \\
\text { têm capacitação para trabalhar o conteúdo de maneira } \\
\text { interdisciplinar. A infraestrutura do laboratório era precária na minha } \\
\text { época. Havia inúmeros instrumentos no laboratório de Física que não } \\
\text { funcionavam (R10). }\end{array}$ \\
\hline $\begin{array}{l}\text { Falta de inserção no cotidiano } \\
\text { escolar }\end{array}$ & $\begin{array}{l}\text { Pontos fracos (durante minha graduação, faz tempo...): carência nas } \\
\text { aulas práticas e experimentos no laboratório; carga horária reduzida } \\
\text { em disciplinas de base como: cálculos I, II e III, fundamentos de } \\
\text { matemática, química e claro de física; pouco conhecimento da vivência } \\
\text { do cotidiano escolar; desconhecimento a respeito das políticas das } \\
\text { escolas municipais e estaduais }(\mathrm{R} 13) \text {. }\end{array}$ \\
\hline $\begin{array}{l}\text { Nada a declarar, não respondeu e } \\
\text { resposta evasiva }\end{array}$ & $\begin{array}{l}\text { Fraco: a falta que a UFMT tem em oferecer mais cursos para outros } \\
\text { municípios (R14). }\end{array}$ \\
\hline
\end{tabular}

Quadro 5 - Algumas respostas dos egressos em relação aos pontos fracos do curso.

Fonte: Elaborado pelas autoras.

Como podemos observar pelas respostas obtidas, há vários pontos a serem analisados, sendo a organização curricular a mais enunciada pelos egressos do curso. Constatamos que existe uma dualidade na interpretação dos egressos sobre a organização curricular do curso. Enquanto alguns pedem mais ênfase nas disciplinas específicas da sua área de formação, há aqueles que pedem mais disciplinas que abordem os fundamentos da educação, como exemplo citamos o egresso R11 que gostaria que o curso se aprofundasse em disciplinas como História da Educação. Esse egresso também destaca como negativo a ênfase dada à Matemática nos módulos comuns do curso. Em relação a essa organização do curso alguns egressos, como o R17, destacam a necessidade de reestruturar o mesmo. As falas apontam ainda para a necessidade de se rever o tempo das disciplinas, a articulação entre os eixos e conteúdos e os estágios de modo a se atingir a formação desejada.

A necessidade de aprofundamento em alguns conteúdos específicos também é enunciada por alguns egressos, a exemplo das falas de R40, que destaca que o curso deveria ter pelo menos 5 anos de duração, e de R12, que afirma que a duração do curso é insuficiente. Há o destaque também para o fato de que a parte comum do curso (dois primeiros anos) deixa a desejar em relação a disciplinas voltadas para a Física, isso pode ser observado, por exemplo, na fala de R60, que aponta a falta de uma base de Física para trabalhar as Ciências no ensino 
fundamental, e também na fala de R19, ambos da habilitação Matemática. A colocação de R60 reitera as falas anteriores e nos leva a refletir sobre a ampla habilitação possibilitada pelo curso, tendo em vista o seu tempo de duração.

A discussão sobre as disciplinas e os saberes que compõem um curso de licenciatura são objeto de estudo de várias pesquisas sobre a formação inicial de professores. Autores como Shulman (1986), Imbernón (2004), Tardif (2014), Nacarato e Paiva (2008), dentre outros, enfatizam que os professores em suas práticas se apoiam em saberes heterogêneos que provém de fontes diversas, sendo necessário conhecer e operar com diferentes práticas e saberes. Entendemos que a palavra "saber" carrega em si "um sentido amplo, que engloba os conhecimentos, as competências, as habilidades (ou aptidões) e as atitudes, isto é, aquilo que muitas vezes foi chamado de saber, saber-fazer e saber-ser" (TARDIF, 2014, p. 255). Neste sentido, um curso de formação de professores que se proponha interdisciplinar precisa abarcar um conjunto de saberes complexos que possibilitem ao licenciando o exercício da autonomia e, principalmente, que favoreça a construção de sua emancipação profissional. Emancipação que lhe possibilite fazer escolhas, buscar por novos conhecimentos e metodologias e continuar sua formação de modo contínuo sem a ingênua crença de que com o curso de licenciatura dominaria toda a quantidade e complexidade de saberes necessários para o exercício da prática docente.

Apesar das limitações apresentadas, destacamos que a maioria dos egressos entrevistados se mostram aptos a trabalhar nas áreas de Ciências e Matemática de forma integrada, como apontado por Trevisan e Dalcin (2017). Isso indica que a proposta é potencialmente viável e que esses egressos possuem pré-disposição para a efetivação de práticas pedagógicas que favorecem a interdisciplinaridade.

O egresso R63 traz como ponto fraco do curso sua não aceitação como professor de Ciências pela comunidade escolar, o que consideramos um fato que precisa ser problematizado e cuja solução é urgente. No diploma expedido pela universidade o egresso recebe o grau de Licenciado em Ciências Naturais e Matemática, com a habilitação específica em Matemática, Física ou Química, o que lhe concede direito de lecionar a disciplina de Ciências e Matemática nos anos finais do ensino fundamental e a disciplina de sua habilitação específica no ensino médio, que no caso de R63 seria Matemática. Tal formação está amparada por todas as normativas que regulam a formação de professores no país, no entanto, os concursos públicos e as redes de ensino ainda não se adaptaram e/ou desconsideram tais normativas.

Outro elemento apontado nas respostas diz respeito aos professores do curso e a contradição sob os modos como os egressos os percebem. Para a maioria dos egressos 
respondentes os professores do curso são tidos como comprometidos e bem preparados, isso foi elencado como um dos pontos fortes do curso. No entanto, quando questionados sobre os pontos fracos também encontramos algumas respostas que dizem que a maioria dos professores não estão preparados para trabalhar no curso de LCNM, Câmpus de Sinop, de forma interdisciplinar, como pode ser observado na resposta de R10. O egresso R27 destaca que o ponto forte do curso é a tentativa de interdisciplinaridade e que seu ponto fraco é a falta dela, ou seja, ele aponta para uma falha do curso, que foi pensado para ser interdisciplinar. Também destacamos a colocação de R33 que aponta que alguns professores que atuam no curso não acreditam em seu potencial.

Essas colocações vêm ao encontro da pesquisa realizada por Barbosa (2012), em que o autor analisa o processo de implantação do curso LCNM. Em sua pesquisa fica claro que muitos professores foram surpreendidos com a proposta de curso a ser implantada em Sinop e que houve uma rejeição inicial à proposta por alguns professores que iriam atuar no curso.

Outra enunciação pertinente é a de R43 que destaca a questão do estágio na disciplina que não é da habilitação do licenciando. Essa situação se deve ao fato de que todos, independentemente de sua habilitação, precisam realizar o estágio de regência em Ciências e Matemática no ensino fundamental, até mesmo porque serão habilitados a atuarem nessas disciplinas. Sua colocação recai novamente na questão da ampla habilitação dos egressos do curso e na necessidade de ampliação da carga horária do mesmo, o que mostra o quanto é latente a necessidade de discussões mais aprofundadas sobre isso.

R43 também destaca a questão dos eixos temáticos que organizam o curso. Ele chama a atenção para o fato de que muitos alunos reprovam em algumas disciplinas e não conseguem cursar o módulo em sua integridade durante os semestres seguintes, o que acaba tornando sem sentido essa organização. Isso é uma questão relevante a ser problematizada pelo Núcleo Docente Estruturante (NDE) do curso, tendo em vista que é a organização temática dos módulos que possibilita a interdisciplinaridade no desenvolvimento do curso. Isso pode ser observado no Projeto Pedagógico do Curso: "Primeiramente a formação do professor de ciências no curso proposto é abordado diante de uma dimensão inter e transdisciplinar assumindo uma metodologia curricular por eixos temáticos e não por disciplinas isoladas” (UFMT, 2009, p. 1112).

Em relação à estrutura física da universidade podemos dizer que foi melhorando ao longo do tempo, mas que as turmas iniciais foram bastante prejudicadas com a carência dessa estrutura. As falas dos egressos das primeiras turmas sinalizaram para a precariedade, como a colocação de R3 e R44. Mas também observamos na colocação de R5 e R36 que, na sua época 
de estudante, apesar de possuir estrutura física, não foi suficientemente aproveitada, isso porque os laboratórios eram pouco utilizados.

R46 destaca alguns problemas como a falta de livros na biblioteca, o que atualmente parece ter sido superado, pois está em andamento a ampliação do espaço físico da biblioteca para acomodar todo o acervo disponível aos alunos do câmpus.

A falta de eventos e projetos relacionados ao curso é outro elemento apontado. Essa questão, nos parece que, recentemente, vem tomando outros rumos, principalmente com o desenvolvimento de projetos financiados pela Fundação de Amparo à Pesquisa do Estado de Mato Grosso (FAPEMAT), coordenados por docentes ligados ao curso, bem como pela realização bianual do Colóquio de Ciências Naturais e Matemática (COCIN), que no ano de 2019 esteve em sua quarta edição. O crescimento de atividades de natureza acadêmicocientífica foi se dando gradativamente a partir do envolvimento de professores e estudantes com o câmpus e com o curso.

No entanto, algumas questões ainda merecem atenção, como a falta de atendimento administrativo no período noturno e os altos índices de evasão do curso, que não se caracteriza como um problema exclusivo desse curso, mas sim das licenciaturas de um modo geral. Araújo e Vianna (2011), no entanto, destacam que um problema maior do que a evasão dos licenciandos da universidade é a evasão dos licenciados das escolas brasileiras, e isso tem sido uma realidade bastante comum e preocupante.

Os pontos levantados sobre o curso indicam problemas que necessitam ser resolvidos ou superados, mas indicam também potencialidades que precisam ser valorizadas. A formação inicial de professores ainda representa um desafio para as políticas públicas, no entanto, é a partir do conhecimento de propostas já implementadas e de suas potencialidades e fragilidades que poderemos avançar.

\section{ALGUMAS CONSIDERAÇÕES}

A diversidade de percepções apresentadas em relação ao percurso formativo vivenciado no curso de LCNM demonstra que não há consenso entre seus egressos, o que nos motiva a continuar pensando na formação inicial de professores. Neste sentido é necessário que as experiências vivenciadas pelos estudantes egressos possam ser consideradas nos processos de análise e avaliação, que possam se constituir como elementos para subsidiar a definição de caminhos a serem seguidos visando o desenvolvimento e aprimoramento de uma proposta de formação inicial. 
As potencialidades identificadas precisam ser vistas como elementos de permanência, enquanto as fragilidades enunciadas necessitam ser problematizadas e superadas. É nesse processo que o aperfeiçoamento vai acontecendo, e isso é muito importante para o estabelecimento de propostas que visem a formação inicial em perspectiva inovadora. Esperase que este estudo possa contribuir para a problematização da formação de professores, bem como para o delineamento de propostas tidas como interdisciplinares.

O curso em questão é uma licenciatura interdisciplinar. que apresenta uma nova perspectiva e possibilidade de formação de professores. Essa proposta favorece a aproximação de professores de diferentes áreas e o desenvolvimento de um trabalho coletivo, tendo em vista sua organização. A articulação do conhecimento também é favorecida nesse tipo de proposta.

No entanto, algumas questões necessitam ser repensadas, como a sua ampla formação que se constitui como uma questão a ser problematizada, considerando o tempo e a formação pretendida (Ciências e Matemática para atender os anos finais do ensino fundamental e Matemática, Física ou Química, para atender ao ensino médio).

A flexibilização do currículo se mostra algo positivo para o desenvolvimento dessa proposta. A possibilidade de o licenciando poder traçar seu percurso de formação, tendo em vista o estabelecimento de créditos mínimos necessários e a abertura de possibilidades de percursos formativos poderia resolver, em parte, o problema advindo das diferentes necessidades apontadas pelos egressos. No entanto, vale ressaltar que isso demandaria a contratação de mais professores e investimentos estruturais na universidade.

É pertinente destacar que no Brasil não há diretrizes curriculares para cursos de LCN, o que tem dificultado ou até mesmo impedido uma avaliação mais coerente com as especificidades desse tipo de organização curricular. Nesse sentido, as políticas públicas que indicam a necessidade de formar professores que fomentem a integração dos conhecimentos, ao mesmo tempo não têm facilitado ou estimulado a implementação de propostas inovadoras.

Consideramos que o ponto alto da proposta é a possibilidade de articulação entre as áreas de conhecimento e o favorecimento de práticas interdisciplinares. A busca pela interdisciplinaridade deve ser valorizada e suas limitações devem ser encaradas como desafios próprios de uma proposta desta natureza. 


\section{REFERÊNCIAS}

ARAÚJO, R. S.; VIANNA, D. M. A história da legislação dos cursos de licenciatura em física no Brasil: do colonial presencial ao digital a distância. Revista Brasileira de Ensino de Física, v. 32, n. 4, 2010.Disponível em: http://www.scielo.br/pdf/rbef/v32n4/10.pdf.Acesso em: 10 mar. 2019.

ARAÚJO, R. S.; VIANNA, D. M. A carência de professores de Ciências e Matemática na Educação Básica e a ampliação das vagas no ensino superior. Ciência \& Educação, v. 17, n. 4, p. 807-822, 2011.Disponível em: http://www.scielo.br/pdf/ciedu/v17n4/a03v17n4.pdf.Acesso em: 18 mar. 2019.

BARBOSA, E. P. Leituras sobre o processo de implantação de uma licenciatura em ciências naturais e matemática por área do conhecimento. (Tese de Doutorado). Universidade Estadual Paulista. Instituto de Geociências e Ciências Exatas, Rio Claro, 2012.311f. Disponível em:

https://repositorio.unesp.br/bitstream/handle/11449/102116/barbosa_ep_dr_rcla.pdf?sequence =1\&isAllowed=y. Acesso em: 10 fev. 2015.

BORGES, L. F. F. Um currículo para a formação de professores. In: VEIGA, I. P. A.; SILVA, E. F. (Orgs). A escola mudou. Que mude a formação de professores! 3 ed. Campinas, SP: Papirus, 2012.

BRASIL. Resolução CNE/CP n ${ }^{\circ}$, de 18 de fevereiro de 2002. Conselho Nacional de Educação Pleno. 2002.

BRASIL. Diretrizes Gerais do Programa de Apoio a Planos de Reestruturação e Expansão das Universidades Federais. 2007.

BRASIL. Conselho Nacional de Educação. Câmara de Educação Básica. Resolução nº 2, de 30 de janeiro de 2012. Ministério da Educação. 2012.

BRASIL. Conselho Nacional de Educação. Parecer CNE/CP nº 2, de 25 de junho de 2015. Ministério da Educação. 2015.

BRASIL. Conselho Nacional de Educação. Resolução CNE/CP nº 2, de 01 de julho de 2015. Ministério da Educação. 2015.

BRASIL. Base Nacional Comum Curricular (BNCC). Educação é a Base. Brasília, MEC/CONSED/UNDIME. 2017a. Disponível em:http://basenacionalcomum.mec.gov.br/images/BNCC_EI_EF_110518_versaofinal_site.pd f. Acesso em: 03 jul. 2017.

BRASIL. Base Nacional Comum Curricular (BNCC). Educação é a Base - Ensino Médio. Brasília, MEC/CONSED/UNDIME. 2017b. Disponível em: http://basenacionalcomum.mec.gov.br/images/historico/BNCC_EnsinoMedio_embaixa_site 110518.pdf.Acesso em: 03 jul. 2017.

GATTI, B. A.; BARRETO, E. S. S.; ANDRÉ, M. E. D. A. Políticas docentes no Brasil: um estado da arte. Brasília: UNESCO, 2011. 
IMBERNÓN, F. Formação docente e profissional: formar-se para a mudança e a incerteza. São Paulo: Cortez, 2004.

IMBERNON, R. A. L.; GUIMARÃES, E. M.; GALVÃO, R. M. S.; LIMA, A. C.;

SANTIAGO, L. F.; JANNUZZI, C. M. L. Um panorama dos cursos de Licenciatura em Ciências Naturais (LCN) no Brasil a partir do $2^{\circ}$ Seminário Brasileiro de Integração de Cursos de LCN/2010. Experiências em Ensino de Ciências. v. 6, pp. 85-93. 2011.

LIMA, J. O. G.; LEITE, L. R. Historicidade dos cursos de Licenciatura no Brasil e sua repercussão na formação do professor de Química. REnCiMa, v. 9, n. 3, p. 143-162, 2018.Disponível em: http://revistapos.cruzeirodosul.edu.br/index.php/rencima/article/view/1483/1006.

Acesso em: 05 out. 2018.

MAGALHÃES JÚNIOR, C. A. O. \& OLIVEIRA, M. P. P. Políticas educacionais e história da formação e atuação de professores para a disciplina de ciências. Associação Brasileira de Pesquisa em Educação em Ciências Atas do V ENPEC, n. 5, 2005.

MASOLA, W. J.; ALLEVATO, N. S. G. Educação Superior no Brasil: traços da história. REnCiMa, v. 8, n. 1, p. 98-108. 2017. Disponível em: http://revistapos.cruzeirodosul.edu.br/index.php/rencima/article/view/1180/872 Acesso em: 05 out. 2018.

MONTEIRO, A. C. R.; PASSOS, L. F. Contexto histórico dos cursos superiores de matemática no Brasil: formação do professor e diversidade cultural. Anais do XI Encontro Nacional de Educação Matemática. Curitiba, PR, 2013.

NACARATO, A. M. \& PAIVA, M. A. V. ( Orgs). A formação do professor que ensina matemática: perspectivas e pesquisas. São Paulo: Autêntica, 2008.

SHULMAN, L. Those who understand: the knowledge growths in teaching. Educational Researcher, v. 15, n. 2, 1986.

SILVA, C. M. S. Formação de professores e pesquisadores de matemática na Faculdade Nacional de Filosofia. Cadernos de Pesquisa. n. 117, p. 103-126, 2002. Disponível em: http://publicacoes.fcc.org.br/ojs/index.php/cp/article/view/545/547. Acesso em: 18 fev. 2018.

SOARES, F. Ensino de matemática e docência nos oitocentos. In: FERREIRA, A. C.; BRITO, A. J.; MIORIM, M. A. (Orgs). Histórias de formação de professores que ensinaram matemática no Brasil. Campinas: Ílion, 2012.

PEREIRA, J. E. D. As licenciaturas e as novas políticas educacionais para a formação docente. Educação \& Sociedade. Ano XX, n. 68, 1999.

TANURI, L. M. História da formação de professores. Revista Brasileira de Educação. n. 14, 2000.Disponível em: http://www.scielo.br/pdf/rbedu/n14/n14a05.pdf. Acesso em: 15 fev. 2018.

TARDIF, M. Saberes docentes e formação profissional. 16 ed. Petrópolis, RJ: Vozes, 2014. 
TREVISAN, A. C. R.; DALCIN, A.O Professor que ensina Matemática e Ciências: A formação por área de conhecimento em questão. Anais do VII Congresso Internacional de Ensino da Matemática, ULBRA, Canoas, RS. 2017. Disponível em:

http://www.conferencias.ulbra.br/index.php/ciem/vii/paper/viewFile/6712/3051. Acesso em: 15 jan. 2019.

TREVISAN. A. C. R. Formação Inicial Interdisciplinar de Professores de Ciências e Matemática; Ressonâncias na Educação Básica. 2018. 174 f. Tese (Doutorado) Universidade Federal de Mato Grosso, Universidade Federal do Pará, Universidade do Estado do Amazonas, Rede Amazônica de Educação em Ciências e Matemática, Programa de PósGraduação em Educação em Ciências e Matemática, Cuiabá, 2018. Disponível em: https://www1.ufmt.br/ufmt/unidade/userfiles/publicacoes/3bedee061c4e93b8dfaaeb9c55c9e921.pdf. Acesso em: 10 jan. 2019.

UNIVERSIDADE FEDERAL DE MATO GROSSO, UFMT. Projeto Pedagógico de Curso (PPC). Curso de Licenciatura em Ciências Naturais e Matemática da Universidade Federal de Mato Grosso, 2009.

VEIGA, I. P. A.; VIANA, C. M. Q. Q. Formação de professores: um campo de possibilidades inovadoras. In: VEIGA, I. P. A.; SILVA, E. F. (Orgs). A escola mudou. Que mude a formação de professores! 3 ed. Campinas, SP: Papirus, 2012.

Submetido em: 06 de março de 2020.

Aprovado em: 31 de março de 2020. 